\title{
Bur open Managing waiting times in diagnostic medical imaging
}

\author{
Sabina Nuti, Milena Vainieri
}

To cite: Nuti S, Vainieri M. Managing waiting times in diagnostic medical imaging. BMJ Open 2012;2:e001255. doi:10.1136/bmjopen-2012001255

- Prepublication history and additional material for this paper are available online. To view these files please visit the journal online (http://dx.doi.org/10.1136/ bmjopen-2012-001255).

Received 4 April 2012 Revised 8 November 2012 Accepted 12 November 2012

This final article is available for use under the terms of the Creative Commons Attribution Non-Commercial 2.0 Licence; see http://bmjopen.bmj.com

Laboratorio Management e Sanità, Institute of Management, Scuola Superiore Sant'Anna, Pisa, Italy

Correspondence to Dr Milena Vainieri; m.vainieri@sssup.it

\section{ABSTRACT}

Objective: This paper aims to analyse the variation in the delivery of diagnostic imaging services in order to suggest possible solutions for the reduction of waiting times, increase the quality of services and reduce financial costs.

Design: This study provides a logic model to manage waiting times in a regional context. Waiting times measured per day were compared on the basis of the variability in the use rates of $\mathrm{CT}$ and MRI examinations in Tuscany for the population, as well as on the basis of the capacity offered with respect to the number of radiologists available. The analysis was performed at the local health authority level to support the decisionmaking process of local managers.

Setting: Diagnostic imaging services, in particular the CT and MRI examinations. The study involved all the

12 local health authorities that provide services for 3.7 million inhabitants of the Italian Tuscany Region.

Primary and secondary outcome measures:

Participants: the study uses regional administrative data on outpatients and survey data on inpatient diagnostic examinations in order to measure productivity.

Primary and secondary outcome measures: The study uses the volumes per 1000 inhabitants, the days of waiting times and the number of examinations per radiologist. Variability was measured using the traditional SD measures.

Results: A significant variation in areas considered homogeneous in terms of age, gender or mortality may indicate that the use of radiological services is not optimal and underuse or overuse occurs and that there is room for improvement in the service organisation.

Conclusions: Considering that there is a high level of variability among district use rates and waiting times, this study provides managers with a specific tool to find the cause of the problem, identify a possible solution, assess the financial impact and initiate the eventual reduction of waste.

\section{BACKGROUND}

The epidemiological changes of the last 30 years have caused a reduction in acute care for populations and an exponential growth in the number of outpatient and diagnostic services. Moreover, technological innovations in the diagnostic sector have

\section{ARTICLE SUMMARY}

Article focus

- Which factors explain the variability in waiting times and in the use of CT and MRI examination rates? This article aims to analyse the relationships among radiologists' productivity, use rates and waiting times in the Tuscan Region.

- Moreover, it proposes a logical tool to help managers deal with this complex issue.

\section{Key messages}

- The results reveal a high level of variability among the disability insurance use rates of local health authorities.

- The factors that may affect these results do not involve private providers or substitution effects between similar procedures.

- Monitoring the appropriateness phase of the prescription becomes critical when it is difficult to ensure acceptable waiting times which could be due to high volumes of the diagnostic imaging services delivered or may depend on inefficiency or a lack of professional resources (eg, the number of radiologists).

- In Tuscany there is no correlation among scans/ radiologists, volumes and waiting times.

- This could lead to the hypothesis that the management of waiting times cannot be generalised and depends on other factors that are strictly related to the local organisational decisions.

- Finally, the paper proposes a logical framework to help policy makers and managers cope with waiting times and appropriateness.

Strengths and limitations of this study

- This study analyses the variation on diagnostic imaging services throughout different perspectives (volumes, waiting times and productivity).

- It provides policy makers with a logical model to manage this variation.

- Limitations regard the generalisation of results, as part of them may be referred only to the organisational features of the region analysed (as for the productivity).

made services more efficient, but at the same time more expensive, thus increasing costs.

Citizens and physicians increasingly request diagnostic services, often without considering their possible negative effects, 
such as radiation caused by CT examinations. It appears that the offer of diagnostic services does not cover the demand from patients, thus causing waiting lists to be increasingly longer and patients to be highly unsatisfied.

Policy makers must therefore face a complex situation resulting from longer waiting times, the increasing demand of diagnostic services from patients and increasing costs.

Which mechanisms may be adopted in order to face such situations and assist managers of public health systems to identify the causes of the problem and possible solutions?

On the one hand, the regional health system, with a universal coverage mission, should provide an adequate number of diagnostic imaging (DI) services to grant equity of access to all citizens and should deliver such services in a timely manner and according to patients' needs. On the other hand, it should reduce the patients' radiation exposure and the inappropriate duplication of examinations as much as possible.

The WHO argues that the use rates of DI services should be adapted to the local needs and should be determined by (1) the type and size of the hospital; (2) the number and type of patients: disease burden, inpatients and outpatients and (3) the therapeutic capabilities. Guyatt et al underlined the importance of accounting for the reassuring effect of an investigation on the wellness of a worried patient, while $\mathrm{Hendel}^{2}$ suggested that intangible factors, local practice and clinical judgement must be carefully considered in the DI procedure appropriateness assessment.

Certainly, the huge growth of DI procedures observed in the last few years raises concern about a possible overuse of these services. ${ }^{2-5}$ According to the European referral guidelines for imaging, the causes of DI service overuse are multiple: repeated investigations, investigations performed although unlikely to affect patient management and premature or incorrect investigations.

Miller $^{3}$ and Lysdahl and Børretzen ${ }^{6}$ observed that the number of supplied DI services is very different among geographical areas and that, often, geographical areas that supply a larger number of DI services do not present better health outcomes for the inhabitants. Song $e t a l^{7}$ reported that there was no evidence of a survival benefit among people who moved to regions with a higher-intensity level of procedures compared to those who moved to lower-intensity regions.

These results suggest that the analysis of the DI services variability across geographical regions could be an important step towards the understanding of the primary determinants of DI procedure growth rates and towards a definition of appropriate use standards. A significant variation in areas considered homogeneous in terms of age, gender or mortality may indicate that the use of radiological services is not optimal and underuse or overuse occurs.
This paper presents the results of a research project aiming at exploring the factors that explain the variability in waiting times and the use of CT and MRI examination rates in Tuscany. The final purpose of the project is to support the regional administration planning process regarding resource allocation and to set standards and gals for local health authorities (LHAs).

\section{TUSCAN CONTEXT AND THE RESEARCH QUESTIONS}

The Italian National Health System is based on the principle of universal coverage and it is financed by general taxation. Following the decentralisation process that started in the 1990 s, regions are responsible for organising and providing healthcare services, while the national level has to ensure universal coverage for the whole population. In total, $82 \%$ of healthcare expenditure is public (Source: OECD data 2009). The remaining $18 \%$ of private expenses for healthcare mainly concerns dental care and some other few specialist visits, copayment and drugs. Healthcare services can be provided by both private and public institutions, their mix varies within Italian regions. In Tuscany over $90 \%$ of services are provided by public institutions.

In particular, CT and MRI examinations are mainly covered by public expenditure and the few private providers of diagnostic imaging services work under contract with the public health authorities. The last Italian survey on citizens' behaviour and consumptions, carried out on 2005 by the Italian National Institute of Statistics, demonstrated that more than $80 \%$ of diagnostic services are covered by public expenditure and copayment. The percentage of DI covered by out of pocket varies across Italian regions. In Tuscany the percentage is about $16 \%$ (vs the Italian average of $20 \%$ ), thus only a minor number of DI services is not registered into the regional administrative data. ${ }^{8}$

The Tuscan region reallocates resources among LHAs using the regional capitation formula. Hence, LHAs are responsible for the resource allocation process of all the healthcare services. To achieve this task, LHAs are in charge of organising the supply structure and consequently they define the number of specialists and the equipment to be dedicated to diagnostic imaging.

The overall economic value of services such as CT and MRI in Tuscany is around 65 million Euros (about $1 \%$ of the regional budget). The volume of these services for the 3.7 million of residents is one of the highest in Italy (Italian Ministry of Health www.salute.gov.it). Despite high volumes, the actual offerings in Tuscany seem to not be enough.

In 2010, waiting times in Tuscany were more than 60 days on average; however, for some LHAs, waiting times reached up to 90 days; variability appeared to be very great: waiting times went from 14 to 260 days. Moreover, citizens claim that waiting times are quite long; this is the main reason why some of them choose 
the private supplier (see, for instance, the results of 2005 survey directed to population ${ }^{9}$ ).

Tuscan policy makers, therefore, consider waiting times to be one of the most important challenges to achieve, also because the National Government requested these diagnostic services to be delivered to patients within 30 days (Piano Nazionale di Governo delle Liste di Attesa-PNGLA 2010-2012).

As regards the use rates per inhabitant standardised by age and sex, great variability (for MRI and CT) was registered in 2009 and 2010: CT use rates went from 45 to 88 per 1000 inhabitants, while the MRI use rates went from 56 to 83 per 1000 inhabitants.

The results indicate that, although Tuscany is a homogeneous territory from a sociodemographic perspective and represents excellence within the Italian regions in terms of quality of healthcare and governance,${ }^{10}$ there is great variability across the region in terms of both waiting times and DI use rates.

Geographical variation in the DI use rates may constitute overuse or underuse with a consequent risk of inappropriateness of the service. ${ }^{6}$ Bhargavan and Sunshine ${ }^{11}$ highlighted great variability in the provision of DI services across areas and suggested that the use of appropriateness criteria, such as those defined by the American College of Radiology (ACR), may minimise these differences. Moreover, they explored this variability to highlight the state-level variables that affect it most, and they observed that the greater the number of Medicare providers, the greater the DI investigation rate per 1000 inhabitants. However, it is worth highlighting that the variability across regions could be affected by other factors like the availability of diagnostic technologies, socioeconomic factors (ie, education and income) or the number of radiologists in the region. ${ }^{6}{ }^{12}$ Moreover, Lysdahl and Børretzen ${ }^{6}$ observed that each area may present a propensity towards a particular procedure considered a reasonable approach for a specific indication, which may lead each area to present a substitution effect among procedures types. On the contrary, it is found that the high use of one modality does not correspond with low use of an alternative modality for specific organs (locations), supporting the assumption that overuse really exists in high-use areas, thus leading to potentially inappropriate resource allocation.

In 2010, the Tuscan region evaluated as inappropriate district areas that registered use rates of the diagnostic imaging services far from the regional median use rate. Those districts may face the risk of an excessive number of radiation exposures (in the case that they are above the median) or a lack of services (in the case that they are lower than the median). ${ }^{13}$ This assumption yields some disadvantages because it does not take into account differences in medical procedures, where any decision involves a certain degree of discretion, the disease burden of particular areas or patient preferences and outcomes. ${ }^{14}$ However, Lysdahl and Børretzen ${ }^{6}$ observed that the number of supplied DI services did not correspond to better health outcomes for inhabitants. Moreover, Song et $a l^{7}$ found that the mortality rate was not lower in areas presenting a high intensity of practices, as one could expect. Low-intensity and high-intensity areas present similar outcomes and, after 3 years, there is no evidence of a survival benefit among people who moved to higherintensity regions compared to those who moved to lower intensity regions.

Considering these premises, the present research investigated the relationship between volumes and waiting times to find out if long waiting times are determined by high volumes of diagnostic services delivered to residents, as well as to assess the impact of factors such as the presence of private suppliers and providers. Some authors ${ }^{15} 16$ suggest that, when coping with variation in healthcare, managers have to show, discuss and monitor data to question professional discretion. Hence, we analysed the following issues:

RQ1: Does variability in the DI rate depend on the presence of private medical providers?

$R Q 2$ : Is there a substitution effect among diagnostic procedures or a problem of procedure mix?

$R Q 3:$ What is the relationship between the volumes delivered and the waiting times?

The most common strategy to reduce waiting times is to increase the supply throughout, on the one hand the enhancement of the production capacity (ie, boosting the opening hours of scans to perform more examinations per scan and increase the number of examinations per radiologist), and on the other hand the increase in personnel/equipment or the contracting out. ${ }^{17}$ Boosting the supply structure may increase the volumes (indeed, capacity is one of the factors that could explain the variability, as reported by scholars $^{6} 121418$ ).

RQ4: Does the number of radiologists and scans available for each LHA or the percentage of services contracted out affect volumes and waiting times?

$R Q 5$ : Which tool may support policy makers and managers to cope with demand and waiting times?

This paper presents some first evidence regarding the questions suggested and proposes a method to enhance the professional consciousness of specialists towards better resource allocation and performance management.

\section{METHODS}

This study is based on empirical analyses. Data sources are both administrative data and surveys. Outpatient dataset includes all DI services provided to Tuscan inhabitants (in or out of the region and by public or private institutions) with the only exception of those examinations full paid by patients. According to the last population survey conducted by the Italian National Institute of Statistics (Istat), in Tuscany the percentage of these examinations should be around $16 \%$. 
To detect the first five research questions we run Pearson correlation and analysis of variance (ANOVA) analyses. In particular, we correlated the use rates and the percentage of examinations provided by private institutions for the RQ1, while we correlated the use rates of four couples of procedures for the RQ2. The four couples of potential substitute procedures were selected by radiologists and technical staff considering only the CT and MRI procedures and they are: the CT and MRI of the superior abdomen, the CT and MRI of the head and brain, the CT and MRI of the rachis and spine or the CT and MRI of the facial massive. We performed the one-way ANOVA to detect the variability across and within the CT (MRI) procedures' userates (RQ2). Further analyses for RQ2 were executed considering the 20 more frequent examinations of CT and MRI. This group approximately constitutes $90 \%$ of the total CT and MRI examinations performed in Tuscany in 2009. In addition to this analysis we provided a map of the number of examinations that exceed the regional median use rate per procedure across Tuscan LHAs in terms of financial value, following an approach similar to the one adopted by Nuti et al. ${ }^{19}$

For RQ4 we took into consideration: the number of radiologists and scans per inhabitants, the productivity scores of radiologists and the percentage of private services contracted out.

In particular, to calculate productivity indices two steps were followed.

The first step was to take into account the recommendations of the workload table developed by the Italian National Scientific Community of Radiologists published into an Italian report of $2006 .{ }^{20}$ In this report radiologists, on the basis of their expertise and experience, argued that the time spent running examinations for young patients (less than 5 years old) is $25 \%$ (weight=1.25) greater than the time spent for patients between 5 and 79 years, while the time spent for elderly people (older than 79 years) is $15 \%$ (weight $=1.15$ ). Moreover, patients coming from the emergency department require the presence of radiologists and technicians for a longer period of time (estimated at 25\%, weight $=1.25)$, while inpatients require $15 \%$ (weight $=1.15$ ) of time more than outpatients. The corrected number of examinations was estimated using these weights. Other aspects presented in the workload report refer to some organisational issues, such as the changing room for patients or the presence of nurses, that can optimise the use of scans and personnel time. The research group considered these factors as part of the productivity that can be managed by LHAs, thus the only correction applied to efficiency indices refers to patient characteristics.

The second step regards the personnel. We conducted a survey collecting all personnel working in the DI departments. The personnel dedicated to CT (MRI) services was estimated using the workload table of the 2006 report $^{\mathrm{i}}$ for the current DI examinations (both inpatients and outpatients) per health authority. This table reports the standard time radiologists spent to execute DI examinations. The number of radiologists who deal only with CT (MRI) was estimated using the percentage of CT (MRI) examinations (in terms of time) and the overall working time. The application of these weights and this deductive process of personnel identification were discussed with the research group as well as with the Italian National Scientific Community of Radiologists (SNR-SIRM) in 2011.

For the last research question, we followed the guidelines of an 'interventionist research approach'. This approach aims to solve problems through the construction of models, diagrams, plans, organisations, etc, by means of the direct involvement of researchers and actors in 'participant observations' in the field. ${ }^{21}$ This method is used in a variety of fields: technical sciences, mathematics, operation analysis, clinical medicine and management control. ${ }^{22}$

Professionals were involved in detangling the DI variability and the management of waiting times. Radiologists, technical staff and management staff (such as the health and cost analysts) were involved in the research project.

Researchers facilitated the process, conducted the project while pointing out the questions and the research hypothesis, looked for articles that may support the perceived determinants of variability, collected data and ran statistical analyses to help professionals identify critical factors.

The calculations were based on the Tuscan outpatient dataset and on the Health Authority data for DI inpatients services, scans and personnel (collected by researchers via surveys).

\section{RESULTS}

The starting point of this research was the observation of the large variation in the use rates of outpatient CT and MRI procedures in Tuscany across the LHAs, which is even more drastic across districts. Figure 1 reports the appraisal made by the Tuscan Health System on the CT and MRI use rates in 2009. The colours identify the evaluation on the basis of the distance from the median use rate: better results are positioned closer to the median rate while worst results are positioned farther from the median because of the increasing risk of over/under use. The appraisal is organised into five coloured bands: very good (dark

\footnotetext{
${ }^{\mathrm{i}}$ The table used is at page 12 of the report available on internet (only in Italian, http://www.asppalermo.org/Archivio/circolari/dip_ radiologia/metodo_nomencl_nuovo.pdf access September 2012)). In this report there are 16 groups of examinations, each group has the time requested to the specialist for the execution in terms of minutes and in comparison with the time spent for the chest x-ray that is the reference exam of this table. For instance, the chest x-ray requires $7.1 \mathrm{~min}$, while the CT without contrast requires $19.8 \mathrm{~min}$ (2.8 times longer than the time required for the chest x-ray).
} 


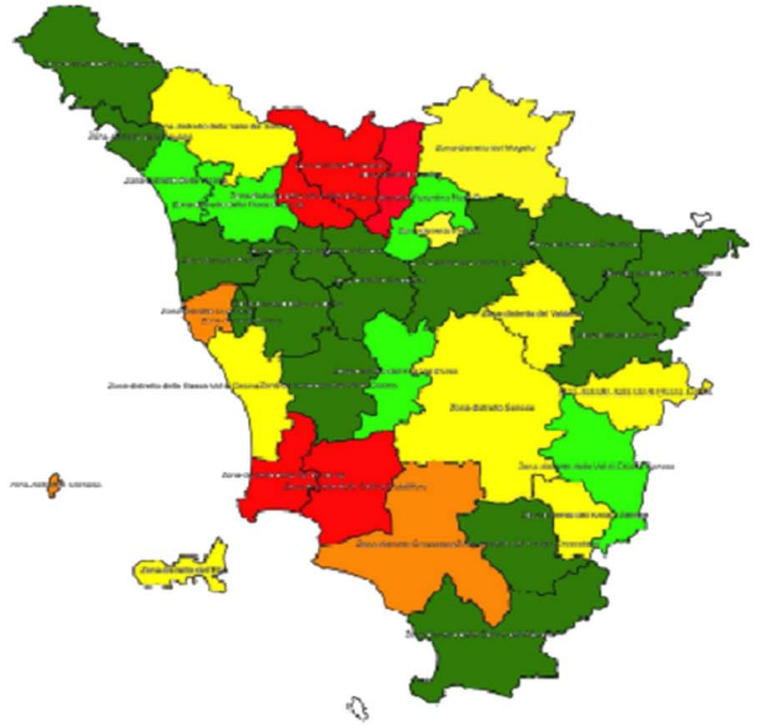

Standardized CT

use-rates per 1000 inhabitants

\begin{tabular}{|c|c|}
\hline 65.94 & 69.79 \\
\hline 62.1 & 65.94 \\
\hline 58.26 & 62.1 \\
\hline 54.41 & 58.26 \\
\hline 46.73 & 54.41 \\
\hline 42.88 & 46.73 \\
\hline \multicolumn{2}{|c|}{$<42.88$} \\
\hline
\end{tabular}

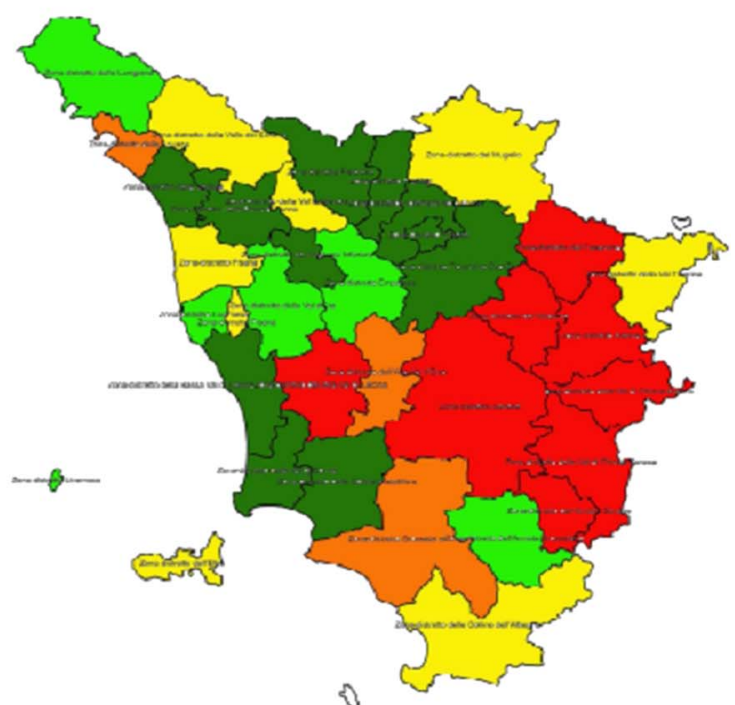

Standardized MRI use-rates per 1000 inhabitants

\begin{tabular}{|c|c|}
\hline 74.95 & 78.89 \\
\hline 71.00 & 74.95 \\
\hline 67.06 & 71.00 \\
\hline 63.11 & 67.06 \\
\hline 55.23 & 63.11 \\
\hline 51.28 & 55.23 \\
\hline \multicolumn{2}{c}{$<51.28$} \\
\hline
\end{tabular}

Figure 1 CT and MRI use rates per 1000 inhabitants in the Tuscan districts.

green); good (green); medium (yellow); bad (organge) and very bad (red) performance.

Was this difference determined by the presence of private institutions? (RQ1) The correlation analysis between the use rates and the percentage of examinations provided by private institutions demonstrates that high use rates do not significantly depend on the private sector's activity: for MRI the correlation was $r=-0.11$ with a $\mathrm{p}=0.727$ and for CT the correlation was $\mathrm{r}=0.072$ with a $\mathrm{p}=0.823$ (see table 4 ). The fact that the presence of the private sector does not influence the variability confirms that it is not up to private providers to increase volumes, because their production is negotiated with the Tuscan LHAs which decide the percentage of services to be provided outside the public structure.

Regarding RQ2, scholars suggest that variability could be due to substitution effects between different modalities. Low-use rates of one modality in the examination of specific organs could generally correspond to high use rates of an alternative modality. However, data do not support this hypothesis; the correlation matrix between two possibly substitutable modalities of analysis indicates that there is no statistically significant correlation between them (table 1). A significant negative correlation would have suggested that high rates of one modality correspond to low rates of the other, suggesting a likely substitution effect between them.

This result is comforting because there should be specific guidelines on the use of each diagnostic modality. The correlation matrix (table 1) also shows that there is positive and significant correlation between the use of some procedures, such as MRI backbone and superior abdomen, across the four groups. Similar results could be found in the literature. ${ }^{6}$

Variability across Health Authorities and their district areas could depend on the over (under) use of specific examinations. Indeed, the one-way ANOVA analysis highlights that there is more variability between procedures (around $90 \%$ for MRI and $71 \%$ for CT) than within them (see table 2).

Hence, the overall variability is mainly due to a different mix of procedures applied by the districts. Looking at the SD across districts for the use-rates of the 20 most recurring procedures, it emerged that procedures with the highest level of variability across local areas are: MRI musculoskeletal; MRI backbone; CT rachis and CT head (see table 3).

Online supplementary appendix 1 for CT and online supplementary appendix 2 for MRI examinations highlights the critical area of inappropriateness for each 
Table 1 Substitution effect between four couples

\begin{tabular}{|c|c|c|c|c|c|c|c|c|c|}
\hline Couples & Investigations & $\begin{array}{l}\text { CT facial } \\
\text { massive }\end{array}$ & $\begin{array}{l}\text { MRI facial } \\
\text { massive }\end{array}$ & $\begin{array}{l}\text { MRI } \\
\text { backbone }\end{array}$ & $\begin{array}{l}\text { CT } \\
\text { rachis }\end{array}$ & $\begin{array}{l}\text { CT } \\
\text { head }\end{array}$ & $\begin{array}{l}\text { MRI } \\
\text { brain }\end{array}$ & $\begin{array}{l}\text { CT superior } \\
\text { abdomen }\end{array}$ & $\begin{array}{l}\text { MRI } \\
\text { superior } \\
\text { abdomen }\end{array}$ \\
\hline 1 & $\begin{array}{l}\text { CT facial } \\
\text { massive }\end{array}$ & 1.00 & & & & & & & \\
\hline 1 & $\begin{array}{l}\text { MRI facial } \\
\text { massive }\end{array}$ & -0.18 & 1.00 & & & & & & \\
\hline 2 & MRI backbone & -0.11 & $0.69^{\star}$ & 1.00 & & & & & \\
\hline 2 & CT rachis & 0.13 & -0.11 & -0.25 & 1.00 & & & & \\
\hline 3 & CT head & $0.44^{*}$ & -0.13 & -0.18 & $0.36^{\star}$ & 1.00 & & & \\
\hline 3 & MRI brain & -0.05 & 0.23 & 0.21 & 0.15 & 0.14 & 1.00 & & \\
\hline 4 & $\begin{array}{l}\text { CT superior } \\
\text { abdomen }\end{array}$ & $0.43^{*}$ & 0.11 & 0.30 & 0.16 & 0.20 & 0.04 & 1.00 & \\
\hline 4 & $\begin{array}{l}\text { MRI superior } \\
\text { abdomen }\end{array}$ & -0.18 & $0.56^{\star}$ & $0.71^{*}$ & 0.09 & -0.21 & -0.07 & 0.31 & 1.00 \\
\hline
\end{tabular}

district, providing managers with the amount of leeway they could obtain if they performed at the regional median.

For example, in the Apuane district, $90 \%$ of its leeway is concentrated on the musculoskeletal MRI, while there is no leeway for some other procedures (such as the Backbone MRI with contrast) because the use-rate is equal or lower than the regional median. At the regional level the resources that can be reallocated for MRI (around 5.5 million Euros) are concentrated (57\%) on the musculoskeletal and backbone examinations, while $42 \%$ of resources for CT (around 6 million Euros) are concentrated on the rachis and complete abdomen with contrast CT examinations.

Once we found out some of the factors that could affect variability in terms of volumes, we looked at the relationship between volumes delivered and waiting times (RQ3). In both the CT and MRI matrix LHAs high use rates are not correlated with longer waiting times. Indeed, the Pearson correlation (table 4) reports an $\mathrm{r}=0.238$ and $\mathrm{p}=0.455$ for $\mathrm{CT}$ and $\mathrm{an} \mathrm{r}=0.11$ and $\mathrm{p}=0.712$ for MRI.

As for the RQ4, table 4 shows that for both CT and MRI examinations the percentage of services delivered by private institutions, the number of scans and radiologists and their efficiency are not correlated with waiting times. Instead, correlations among capacity factors and volumes are different for CT and MRI. In the case of MRI capacity, radiologists and scans per inhabitants and their efficiency are positively correlated with public-use rate. Moreover, the significant negative correlation between the percentage of services delivered by private institutions and the public use rates can be interpreted as a designed strategy of contracting out where private suppliers integrate public offerings.

Unlike MRI services and other studies on variability, ${ }^{14} 18$ CT services in Tuscany seem not to be supply sensitive: the number of radiologists, technical staff per inhabitant, scans and the volumes per inhabitant provided by public providers appear not to influence the demand. It is worth noting that radiologists are employed by LHAs and volumes do not influence their salary.

As regards the strategy of increasing the capacity to reduce waiting times, this seems not to be effective. In particular, it is expected that the contracting out is a strategy applied by LHAs once their production capacity is saturated. Indeed, data show (table 4) that a higher percentage of services delivered by private providers corresponds to a lower radiologists productivity score $(-0.8$ for MRI and -0.7 for CT both with a $\mathrm{p}<0.01)$.

Thus, the recourse to private suppliers appears not to be cost effective in Tuscany. LHAs with low productivity

Table 2 Analysis of variance of both CT and MRI use rates (groups are the procedures)

\begin{tabular}{lllcrlcl}
\hline & Source & SS & Per cent & df & MS & F & Prob>F \\
\hline MRI & Between groups & 0.030646 & 90 & 31 & 0.000989 & 265.17 & 0 \\
& Within groups & 0.003571 & 10 & 958 & $3.73 \mathrm{E}-06$ & \\
& Total & 0.03422 & 100 & 989 & $3.5 \mathrm{E}-05$ & 74.94 \\
$\mathrm{NT}$ & Between groups & 0.005658 & 71 & 27 & 0.00021 & 0 \\
& Within groups & 0.002324 & 29 & 831 & $2.80 \mathrm{E}-06$ & & \\
& Total & 0.00798 & 100 & 858 & $9.30 \mathrm{E}-06$ & \\
\hline
\end{tabular}

MRI Bartlett's test for equal variances: $\chi^{2}(31)=4.1 e+03$ Prob $>\chi^{2}=0.000$

CT Bartlett's test for equal variances: $\chi^{2}(27)=1.5 \mathrm{e}+03$ Prob $>\chi^{2}=0.000$ 
Table 3 List of use rate procedures with the highest SD

\begin{tabular}{ll}
\hline Use rates of & Across districts SDs \\
\hline MRI musculoskeletal & $\mathbf{2 0 0 9}$ \\
MRI backbone & 7.07 \\
CT rachis & 6.95 \\
CT head & 5.02 \\
CT complete abdomen with & 3.6 \\
contrast & 2.92 \\
CT superior abdomen with & 2.55 \\
contrast & \\
CT chest with contrast & 2.1 \\
CT chest & 2.01 \\
CT lower extremity & 1.67 \\
MRI brain & 1.6 \\
MRI brain with contrast & 1.56 \\
CT facial massive & 1.35 \\
CT head with contrast & 0.91 \\
MRI backbone with contrast & 0.72 \\
CT neck with contrast & 0.63 \\
MRI facial massive with contrast & 0.49 \\
MRI musculoskeletal with & 0.48 \\
contrast & \\
Angio MRI & 0.43 \\
MRI superior abdomen with & 0.36 \\
contrast & \\
MRI facial massive & 0.34 \\
\hline
\end{tabular}

per radiologist could increase the number of examinations delivered by their public structures reducing the recourse to private providers. Hence, if all the radiologists working in public institutions had reached the maximum level of productivity, the reduction of examinations delivered by private institutions would have led to savings. Considering the actual number of scans at their maximum level of productivity and the fares of examinations, these savings would have reached up to 10 million Euros (6 million for CT and 5 million for MRI).

In conclusion, the overall Pearson correlation matrix (table 4) highlighted that waiting times do not correlate with the factors selected (volumes, capacity and efficiency). Similar results could be obtained performing the ANOVA analysis on waiting times and volumes, capacity and efficiency (adjusted $\mathrm{R}^{2}$ is $18 \%$, residuals are greater than $50 \%$ and no factor has a $\mathrm{p}<0.05$ ).

The fact that there is no correlation between the scans/radiologists, volumes and waiting times could lead to the hypothesis that the management of waiting times cannot be generalised and will depend on factors that are strictly related to the local organisational decisions.

For the last research question (which tools are necessary to help managers coping with volumes and waiting times), the research team developed a two-dimensional matrix where the $\mathrm{x}$-axis shows the use rate (the volumes per inhabitants) and the y-axis reports the waiting times for CT or MRI.
Using regional medians, the matrix identifies four quadrants.

1. Short waiting times and high volumes per inhabitant

2. Short waiting times and low volumes delivered

3. Long waiting times and high volumes per inhabitant

4. Long waiting times and low volumes delivered

This first classification yields the following hypothesis:

The institutions that belong to the first quadrant could risk delivering inappropriate services and/or have an excessive amount of resources at their disposal.

The institutions belonging to the second quadrant could risk substantially decreasing their supply of services or facing a problem in the quality of their services if their citizens decided to seek such services at other institutions.

The institutions that belong to the third quadrant could face problems in terms of appropriateness and production efficiency (Figure 2).

Finally, the institutions belonging to the forth quadrant could face difficulties in terms of efficiency or inappropriate amount of resources.

Figure 3 illustrates the matrix of both CT and MRI volumes and waiting times. Results and conclusion coming from the analysis of the matrix and correlation for CT and MRI are similar. The figure 3 shows that LHAs are positioned in all the four quadrants for both CT and MRI; this highlights that LHAs can face different problems. Using the above logical framework, some LHAs (eg, 106 and 104 for CT or 102 and 107 for MRI) positioned in the third quadrant (high volumes and high waiting times) could face problems in terms of appropriateness and (low) efficiency. Those LHAs positioned in the forth quadrant (low volume and high waiting times) may face problems relating to their capacity (few personnel and few scans) or (low) efficiency.

\section{CONCLUSIONS}

This paper provides an analysis of the variability in the use rates of CT and MRI examinations in Tuscany. The analysis has been performed at the LHA level (including district areas) to support the decision-making process of local managers.

Results reveal a high level of variability among the LHAs' (and district areas) use rates. Why do some residents use these DI services much more than others? Factors that may affect these results do not involve private providers or substitution effects between similar procedures (correlation analyses were not significant). The ANOVA analysis showed that $71 \%$ for CT and $90 \%$ for MRI of variability are explained between groups (procedures); indeed, the analysis of procedure mix indicates that there are some procedures (eg, CTs of the head) with high level of standard deviations. Thus, the relevant issue is about how to share and increase the responsibility of general practitioners and specialists in the prescription phase. 
Table 4 Overall correlation matrix among volumes, efficiency, capacity, waiting times and recourse to private providers

\begin{tabular}{|c|c|c|c|c|c|c|c|c|c|c|c|c|c|c|c|c|c|c|c|}
\hline \multicolumn{10}{|c|}{ MRI } & \multicolumn{10}{|l|}{ Ст } \\
\hline \multicolumn{3}{|c|}{ Efficiency } & \multicolumn{3}{|c|}{ Capacity } & \multirow[b]{2}{*}{ 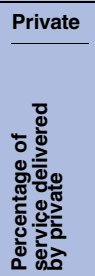 } & \multicolumn{2}{|c|}{ Volumes } & \multirow[t]{2}{*}{ Times } & \multicolumn{3}{|c|}{ Efficiency } & \multicolumn{3}{|c|}{ Capacity } & \multirow[b]{2}{*}{ 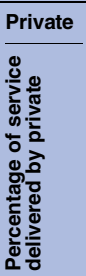 } & \multicolumn{2}{|c|}{ Volumes } & \multirow[b]{2}{*}{ 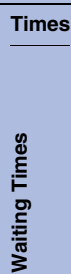 } \\
\hline 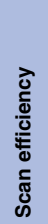 & 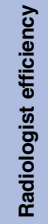 & 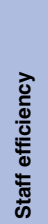 & 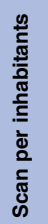 & 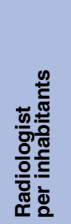 & 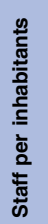 & & 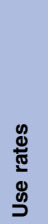 & 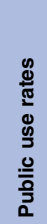 & & 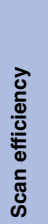 & 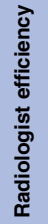 & 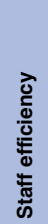 & 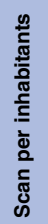 & 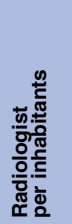 & 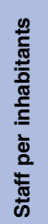 & & 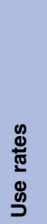 & 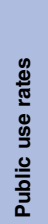 & \\
\hline
\end{tabular}

\begin{tabular}{|c|c|c|c|c|c|c|c|c|c|c|c|c|c|c|c|c|c|c|c|c|}
\hline \multirow[t]{5}{*}{ Efficiency } & $\begin{array}{l}\text { Scan } \\
\text { efficiency }\end{array}$ & 1 & & & & & & & & & 1 & & & & & & & & & \\
\hline & Radiologist & -0.0788 & 1 & & & & & & & & 0.2216 & 1 & & & & & & & & \\
\hline & efficiency & 0.8078 & & & & & & & & & 0.4888 & & & & & & & & & \\
\hline & Staff efficiency & -0.5275 & 0.8131 & 1 & & & & & & & 0.4521 & 0.817 & 1 & & & & & & & \\
\hline & & 0.078 & 0.0013 & & & & & & & & 0.14 & 0.0012 & & & & & & & & \\
\hline \multirow[t]{6}{*}{ Capacity } & Scan per & -0.4495 & 0.8416 & 0.9104 & 1 & & & & & & -0.6173 & 0.4171 & 0.3067 & 1 & & & & & & \\
\hline & inhabitants & 0.1427 & 0.0006 & 0 & & & & & & & 0.0325 & 0.1773 & 0.3322 & & & & & & & \\
\hline & Radiologist per & 0.1887 & 0.4507 & 0.3739 & 0.596 & 1 & & & & & -0.0299 & -0.8122 & -0.4847 & -0.1716 & 1 & & & & & \\
\hline & inhabitants & 0.557 & 0.1414 & 0.2312 & 0.0408 & & & & & & 0.9265 & 0.0013 & 0.1103 & 0.5939 & & & & & & \\
\hline & Staff per & 0.6341 & 0.4748 & 0.02 & 0.2942 & 0.7496 & 1 & & & & -0.3789 & -0.6572 & -0.8259 & -0.057 & 0.6346 & 1 & & & & \\
\hline & inhabitants & 0.0268 & 0.1189 & 0.9508 & 0.3533 & 0.005 & & & & & 0.2246 & 0.0202 & 0.0009 & 0.8604 & 0.0266 & & & & & \\
\hline \multirow[t]{3}{*}{ Private } & Percentage of & 0.28 & -0.8058 & -0.8455 & -0.9191 & -0.741 & -0.4352 & 1 & & & -0.1636 & -0.7513 & -0.7322 & -0.5105 & 0.522 & 0.6129 & 1 & & & \\
\hline & service & 0.3781 & 0.0016 & 0.0005 & 0 & 0.0058 & 0.1573 & & & & 0.6114 & 0.0049 & 0.0068 & 0.0899 & 0.0817 & 0.0341 & & & & \\
\hline & $\begin{array}{l}\text { delivered by } \\
\text { private }\end{array}$ & & & & & & & & & & & & & & & & & & & \\
\hline \multirow[t]{4}{*}{ Volumes } & $\begin{array}{l}\text { private } \\
\text { Use rates }\end{array}$ & 0.5402 & 0.5387 & 0.2023 & 0.1772 & 0.192 & 0.4798 & -0.1129 & 1 & & 0.0957 & -0.4271 & -0.2436 & -0.2243 & 0.4802 & 0.1344 & 0.0725 & 1 & & \\
\hline & & 0.0698 & 0.0707 & 0.5283 & 0.5816 & 0.55 & 0.1144 & 0.7268 & & & 0.7674 & 0.1662 & 0.4456 & 0.4834 & 0.1141 & 0.6772 & 0.8228 & & & \\
\hline & Public use & -0.1335 & 0.9033 & 0.8429 & 0.9149 & 0.7373 & 0.5395 & -0.9633 & 0.3634 & 1 & 0.263 & 0.3699 & 0.5014 & 0.2821 & -0.1249 & -0.4652 & -0.8201 & 0.4483 & 1 & \\
\hline & rates & 0.6792 & 0.0001 & 0.0006 & 0 & 0.0062 & 0.0702 & 0 & 0.2457 & & 0.4089 & 0.2366 & 0.0968 & 0.3743 & 0.6988 & 0.1275 & 0.0011 & 0.1439 & & \\
\hline Waiting & Waiting times & -0.1195 & 0.1737 & 0.188 & 0.2542 & 0.0059 & -0.0321 & -0.0568 & 0.2384 & 0.1315 & -0.0268 & -0.1965 & -0.1096 & -0.274 & 0.0866 & -0.0078 & 0.4088 & 0.1193 & -0.3175 & 1 \\
\hline times & & 0.7113 & 0.5892 & 0.5584 & 0.4253 & 0.9856 & 0.9211 & 0.8607 & 0.4556 & 0.6837 & 0.9341 & 0.5404 & 0.7346 & 0.3887 & 0.789 & 0.9809 & 0.1871 & 0.712 & 0.3145 & \\
\hline
\end{tabular}

$\mathrm{p}$ Values in italics. 


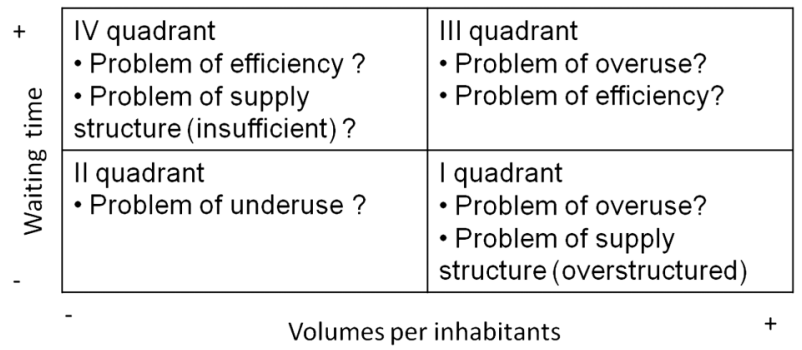

Figure 2 The logical framework to cope with long waiting times and their relationship with volumes.

The monetary value attached to the examinations that exceed the median use rates suggests that there is a broad margin of intervention and the need for policy makers and managers to find new and more effective ways to control appropriateness.

This analysis of use rates is a fundamental step to cope with long waiting times, but it is not enough. Strategies adopted to cope with waiting times usually concern the enhancement of capacity throughout efficiency, the number of scans and radiologists per inhabitants and the contracting out.

This paper proposes a logical approach to identify the critical areas for controlling variability in use rates and to find out if waiting times are determined by inefficiencies, a lack of appropriateness in the prescription phase or a lack of professional resources. The final aim of the paper is to help decision makers define the priorities of intervention. Financial considerations were also added with the aim to both enhance the specialists' competence and the economic consciousness through focus groups, and exploit the learning opportunities by comparing best practices.

The empirical analyses highlighted for both the CT and MRI examinations that waiting times in Tuscany are not affected by volumes or capacities. Moreover, unlike MRI and other studies on specialist care, it seems that the CT is not supply sensitive. Hence, the management of waiting times cannot be generalised and depends on other factors that are strictly related to the local organisational decisions. Moreover, this analysis highlighted that the Tuscan Region has to tackle with variation in volumes and high waiting times optimising the productivity of personnel and scans; this $\mathrm{t}$ can lead to a

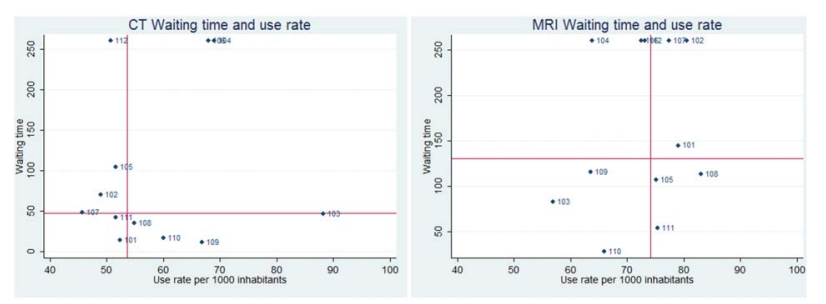

Figure 3 The matrix for waiting times and volumes of CT and MRI. reduction of costs (as a consequence of a reduction of contracting out).

The matrix supports in this paper helped policy makers and top managers to analyse the complex task of coping with long waiting times and appropriateness.

Even if there are some limitations in generalising the results described in this paper, since they could be affected by macro (eg, public system based on universal coverage) and micro (eg, the supply structure) factors linked to the Tuscan context, the matrix proposed can be applied outside this context. The matrix and its logical framework may represent a practical managerial tool that supports the difficult and multi factors analysis of waiting times and appropriateness in delivering outpatient services.

Acknowledgements We thank Dr Claudio Vignali (Director of the radiology department of the LHA 12 of Viareggio), Daniele Di Feo responsible for the radiologist technical staff of Meyer teaching hospital) and all the LHAs' management for their worthy suggestions and collaboration. We also thank the participants of the 'Wennberg International Collaborative Conference' held in London in September 2010. A particular acknowledgement to Professor Gwyn Bevan and Professor David C Goodman for their comments on the earlier version of this paper.

Contributors SN and MV conceived and designed the research. MV analysed the data. SN and MV wrote the paper. SN and MV contributed to the interpretation of data. SN and MV approved the final version of the manuscript.

Funding Funded by Tuscany Region, Italy.

Competing interests None.

Provenance and peer review Not commissioned; externally peer reviewed.

Data sharing statement No additional data are available.

\section{REFERENCES}

1. Guyatt $\mathrm{GH}$, Tugwell PX, Feeny $\mathrm{DH}$, et al. A framework for clinical evaluation of diagnostic technologies. CMAJ 1986;134:587-94.

2. Hendel RC. Utilization management of cardiovascular imaging: pre-certification and appropriateness. J Am Coll Cardiol 2008;1:241-8.

3. Miller MM. MedPAC recommendations on imaging services. Medicare Payment Advisory Commission, 2005.

4. Blackmore CC. Defining quality in radiology. J Am Coll Radiol 2007;4:217-23.

5. Smith-Bindman R, Miglioretti DL, Larson EB. Rising use of diagnostic medical imaging in a large integrated health system. Health Affairs 2008;27:1491-502.

6. Lysdahl KB, Børretzen I. Geographical variation in radiological services: nationwide survey. BMC Health Ser Res 2007:7-21.

7. Song Y, Skinner J, Bynum J, et al. Regional variation in diagnostic procedures. N Engl J Med 2010;363:45-53.

8. Cislaghi C, Giuliani F. Out of pocket sanitario nelle regioni italiane. I uaderni di Monitor 2008;22:161-77.

9. Vainieri M. Che cosa influenza la soddisfazione dei cittadini toscani nei servizi territoriali di base? Salute e Territorio 2006;156:137-56.

10. Censis. I modelli decisionali nella sanità locale. Roma, 2008.

11. Bhargavan $\mathrm{M}$, Sunshine $\mathrm{JH}$. Utilization of radiology services in the United States: levels and trends in modalities, regions and populations. Radiology 2005;234:824-32.

12. Lysdahl KB, Hofmann BM. What causes increasing and unnecessary use of radiological investigations? A survey of radiologists'perceptions. BMC Health Ser Res 2009;9:155.

13. Nuti S, Barsanti S. II Sistema di valutazione della performance della sanità toscana-REPORT 2009 Società della Salute/Zone-Distretto. Pisa: Edizioni ETS, 2010.

14. Wennberg EJ. Tracking medicine. Oxford: University Press, 2010.

15. Bevan $G$, Hollinghurst $S$, Benton $P$, et al. Using information on variation in rates of supply to question professional discretion in public services. Financ Account Manage 2004;20:1-17. 
16. Lee TH. Turning doctors into leaders. Harvard Bus Rev 2010:50-8.

17. Emery DJ, Forster AJ, Shojania KG, et al. Management of MRI Wait Lists in Canada. Healthc Policy 2009;4:76-86.

18. Appleby J, Raleigh V, Frosini F, et al. Variation in healthcare. London: The King's Fund, 2011.

19. Nuti S, Vainieri M, Bonini A. Disinvestment for re-allocation: a process to identify priorities in healthcare. Health Policy 2010;95:137-43.
20. Sirm-Snr. Metodologia di determinazione dei volumi di attività e della produttività dei medici radiologi- Nomenclatore Sirm-Snr Delle Prestazioni Radiologiche. Genova: OMICRON, 2006.

21. Jonsson S, Lukka K. Doing interventionist research in management accounting. Goteborg: Gothenburg Research Institute, 2005.

22. Kasanen E, Lukka K, Siitonen A. The constructive approach in management accounting research. J Manag Acc Res 1993;5 (Fall):243-64 